\title{
Faculty of Educational Sciences' Students' Perception of Faculty Culture
}

\author{
Kürşad YILMAZ* $\quad$ Ebru OĞUZ*
}

\begin{abstract}
The aim of this study is to put forward the perceptions of last year students of Ankara University Faculty of Educational Sciences regarding organizational culture. The study group for the research consisted of 275 Faculty of Education Science last year students. Frequency, T-Test, Kruskal Wallis and Mann Whitney U tests were performed to analyzing the data appropriate to the aim of the research. According to the results obtained, "In a competition against students from the same department of different universities, I feel luckier", "Research assistants at the faculty willingly help the students" are the most positive statements of perceptions. "There is a harmony among departments for applications in our university", "the Faculty administration are successful at problem solving", there were amongst the negative statements of perceptions. Students in the study didn't show a significant difference in perceptions of faculty culture gender wise. The students in the study showed a significant difference in faculty culture according to the department they were in. A Mann Whitney $U$ test between departments returned these results; Guidance and psychological counseling" and "Mentally Disabilities Undergraduate Programme", "Primary School Education" and "Mentally Disabilities Undergraduate Programme", "Social Sciences" and "Computers and Teaching Technology (CTTE)", "CTTE" and "Mentally Disabilities Undergraduate Programme", "Mentally Disabilities Undergraduate Programme" and "Preschool Education" departments showed significance differences.
\end{abstract}

Key Words: Organizational culture, faculty culture, educational organizations, student perceptions

\footnotetext{
${ }^{*}$ Ress. Assist., Ankara University, Faculty of Educational Sciences
} 


\section{SUMMARY}

Organization Cultural aspect is a topic that has been in the limelight for a few years now. Especially since the beginning of the 1980's interest in culture and culture related concepts has increased. Especially organizations and organizational living studies in cooperating culture with point emphasis. To such an extent that studies show a direct relation between organizational culture and organizational success. Moreover it is difficult to view organizations within a community independent of culture. The culture and values of a community, have known effects on organizational management and organizational concept, and a visual effect on management period and practice. People forming organizations incorporate their cultural values into the organization. Thus organizations are affected by cultures of communities they are in and also affect the communities' culture via the individuals inside them. Actually building of relationships through culture, value, norm, language, and similar concepts of an organization is not a trend or a popular condition. Explaining organization and social reality in context to this concept is said to be a paradigmatic change. Generally knowledge has played an important role in the increase of special and management education from criticism of positivism, a popular paradigm. Because positivist is a universal and only view of reality, and reality is an independent value. Basic theory has been taken from the environment and positivism a paradigm in education management has made researchers keep apart value from reality, theory from practical, conscience from rationality as a foundation concept. This understanding, be it in social sciences be it in educational management, has been questioned for a while now (Sargut, 1994; Şimşek, 1997; Şişman, 1998; Balc1, 2003; Turan, 2004).

Culture wise education organizations have had a share of the pie. In researches regarding educational organizations, it has been stressed that educational organizations have to look more like culture communities than mere enterprises. Furthermore educational organizations shouldn't look like the can be all solved by positivism and rational views. According to Sergiovanni and Corbally (1986), organizations should show more irrational traits like culture opposed to rational traits. When analyzing organizations, cultural traits should be taken into consideration. When determining school culture, educational organization culture properties would be appropriate. Educational organizations interact with people as an organizational property. Individuals in an educational organization interact and this property reflects all properties of an organization. This condition is affects organization culture of educational organizations.

In educational organizations, organization culture, educational services offered, educational services taken and organization administration in service are sub cultures that show face to face interaction. When viewed this 
way, educational organizations play an important role in perception realization of organizational culture. This important difference is brought about by an important effect, during student orientations this is determined by students. According to this the aim of the research is; Ankara University Faculty of Educational Sciences last year students perception of faculty culture.

\section{Method}

This research aimed at determining perceptions of university students faculty culture is in the scanning model. The sample group consists of 275 last year students from Ankara University Faculty of Educational Sciences, and they have been distributed age wise.

The scale used in the research was developed by Erdem and İşbaş1 (2001). In the research, frequency, percentage, t-test, Kruskal Wallis and Mann Whitney U-tests analysis tests were done in accordance to the research.

\section{Findings/Results}

According to the results obtained, "In a competition against students from the same department of different universities, I feel luckier" (65.5\%), "The faculty has a positive image outside (campus, city)" (57.5\%), "Research assistants at the faculty willingly help the students" (55.6\%), "Teaching staff treat students like humans" (54.1\%), "To be a student in this faculty of this university is a privilege" $(53.1 \%)$, are the most positive statements of perceptions. "Memories, stories and events about the faculty is passed on to the freshman by the seniors", "The faculty's' physical space is different and authentic compared to other faculties" (60.8\%), "There is a harmony among departments for applications in our university" (56.0\%), "There exist a communication gap between students of different classes" $(52.3 \%)$, "the Faculty administration are successful at problem solving" $(51.3 \%)$, there were amongst the negative statements of perceptions.

When evaluated one by one on the answer scale, the highest "I totally agree" (78) $28.4 \%$ answer was given to, "In a competition against students from the same department of different universities, I feel luckier" question.

Students gave two statements the highest "I agree" answer at $48.5 \%$. These statements were; "Research assistants at the faculty willingly help the students" and "Teaching staff treat students like humans", where 128 students replied to as "I agree". 117 students replied to "There is a harmony among departments for applications in our university" statement with "Not decided" with a ratio of $42.5 \%$. 
Students gave "I don't agree" answer to two different statements with a high ratio of $36.4 \%$. These statements were "Memories, stories and events about the faculty are passed on to the freshman by the seniors" and "Students can freely and sufficiently explain the views and problems to administrator regarding practices in the faculty". 100 students said "I don't agree" to this statement. Students replied "I totally disagree" to the "The faculty's' physical space is different and authentic compared to other faculties" statement. This statement had $72(26.2 \%)$ students replying "I totally disagree".

From the research sample a significant difference was not seen in perceptions of faculty culture in the students with regards to gender $\left[\mathrm{t}_{(150,94)}=1,950, \mathrm{p}>.05\right]$. By this it can be said that there is no significant relationship with gender and faculty culture perceptions. According to results obtained, in the elements that form faculty organizational culture girls and boys are equally affected. Furthermore applications that form faculty cultures are given to girls and boys at the same level. Is this condition valid in faculties where the students get their education? And hence, a Kruskal Wallis analysis was performed to determine whether students perceptions of faculty culture changed in accordance to the faculty of education they were in. This analysis was chosen because the distribution of students wasn't normal.

According to Kruskal Wallis analysis result; students who were in the research sample showed a significant differentiation $\left[\chi^{2}(5)=17,96 \mathrm{p}<.01\right]$ in accordance with faculty culture and the faculty of education they were in. This result denoted that students in different faculties affected their perceptions on faculty culture. Averages of faculty orders/sequence taken showed the highest average with "Teachers for the mentally retarded" and the lowest with the "Computers and department of Teaching Technology". Analysis done here showed a significant difference between departments, but significant differences were in which group determined. Hence all departments were compared with each other.

According to Mann Whitney U-Test analysis results; a significant difference was seen in students from the departments of "Guidance and Psychological Counseling" and "Teaching for The Mentally Retarded", "Class Teachers" and "Teaching for the mentally retarded", "Social sciences Teaching" and "Computers and Teaching Technology", "Computers and teaching Technology" and "Teaching for Mentally retarded", "Teaching for Mentally Retarded" and "Preschool Teaching" departments.

\section{Discussions and Conclusions}

In the research done by Erdem and İşbaşı (2001), the maximum positive answers in descending order, physical environment, ceremonies, humanitarian ways of teaching staff, teaching staff openness to 
dialogue/communication, research assistants concern, the privilege of being a student of the economics and management science faculty were given to these statements. The negative statements were; no cooperation between departments, the methods of other departments not being known, and the method of presentation of class not aimed at developing skill and thinking.

The students in the research samples age and perception of faculty culture did not show a significant difference. The reason for this being, faculty applications divided and performed in equality, or the elements forming faculty culture effects girls and boys at the rate.

Perceptions of faculty culture of students in the research, showed significant difference in accordance to the department they were in. Mann Whitney U-Test analysis results showed a significant difference was seen in students from the departments of "Guidance and Psychological Counseling" and "Teaching for The Mentally Retarded", "Class Teachers" and "Teaching for the mentally retarded", "Social sciences Teaching" and "Computers and Teaching Technology", "Computers and teaching Technology" and "Teaching for Mentally retarded", "Teaching for Mentally Retarded" and "Preschool Teaching" departments. The reason for this difference is due to teaching staff, their attitude, how they conduct classes and their views about other topics. Because the teaching staff of the faculty give classes to various departments and the students are always in contact with them. Organizational culture is affected by culture of individuals in it, and perceptions of organizational culture changes. It isn't easy to think independently in a community of organizations and individuals.

Memories about the faculty, stories and events aren't passed over by old students to new students, faculty physical environment is not different and authentic compared to another faculty, faculty applications are not in harmony within departments, faculty administration aren't successful at problem solving. Hence, administration should solve or cease any problems faced by students. Special meetings to student should be given for the faculty history and other information. The physical environment can be improved to look better and attract attention, department administrative and personnel can come together in events as an example, students from different classes should be brought together in an interactive event. And most important, administration has to work hard on problem solving.

Researches and researches after this, should take into consideration the culture of individuals in their researches. Furthermore studies like this can be developed and expanded by comparing different faculties, different classes, and different departments.

NOTE: This is an extended summary of the following article originally written in Turkish. 


\title{
Eğitim Bilimleri Fakültesi Öğrencilerinin Fakülte Kültürüne İlişkin Algıları
}

\begin{abstract}
Kürşad YILMAZ*
Ebru OĞUZ*

ÖZ. Bu çalışmanın amacı, Ankara Üniversitesi Eğitim Bilimleri Fakültesi son sınıf öğrencilerinin örgüt kültürüne ilişkin algılarını ortaya koymaktır. Araştırmanın çalışma grubu, Eğitim Bilimleri Fakültesi 275 son sınıf öğrencisinden oluşmaktadır. Veri analizinde araştırmanın amacına uygun olarak veriler üzerinde frekans, t-testi, Kruskal Wallis ve Mann Whitney U testleri yapılmıştır. Elde edilen sonuçlara göre en olumlu ifadelerden bazıları;"Diğer üniversitelerin Eğitim Fakültelerinin aynı bölümündeki öğrenciler ile rekabette kendimi şanslı görüyorum", "Fakültenin araştırma görevlileri öğrencilere içtenlikle yardımcı olurlar". Olumsuz olarak görülen ifadelerden bazıları ise "Fakültemizde uygulamalar açısından bölümler arasında yüksek uyum vardır", "Fakültenin yöneticileri sorunların giderilmesinde başarılıdır" gibi maddelerdir. Araştırmaya katılan öğrencilerin fakülte kültürüne ilişkin algıları cinsiyete göre gruplar arasında anlamlı bir farklılık göstermemektedir. Araştırmaya katılan öğrencilerin fakülte kültürüne ilişkin algıları, öğrenim gördükleri bölümlere göre anlamlı bir şekilde farklılaşmaktadır. Bölümler arasında yapılan Mann Whitney U testi sonuçlarına göre; "Rehberlik ve Psikolojik Danışmanlık" ve "Zihin Engelliler Öğretmenliği (ZEÖ)", "Sinıf Öğretmenliği” ve "ZEÖ”, "Sosyal Bilgiler Öğretmenliği”" ve "Bilgisayarlı Öğretim Teknolojileri Eğitimi (BÖTE)", "BÖTE" ve "ZEÖ", "ZEÖ” ve "Okul Öncesi Öğretmenliği” bölümleri arasında anlamlı farklar bulunmuştur.
\end{abstract}

Anahtar Sözcükler: Örgüt kültürü, fakülte kültürü, eğitim örgütleri, öğrenci algıları

\footnotetext{
*Arş. Gör., Ankara Üniversitesi Eğitim Bilimleri Fakültesi EYTEP Anabilim Dalı
} 


\section{GİRIŞ}

Son y1llarda, örgüt ve yönetim yönünden üzerinde en çok durulan konulardan birisi örgütlerin kültürel yönüdür. Özellikle 1980'lerin başından itibaren kültür ve bununla ilgili diğer kavramlara olan ilginin $\operatorname{arttığ} 1$ görülmektedir. Özellikle de örgüt ve örgütsel yaşam ile ilgili birçok çalışmada kültürle ilgili noktalara vurgu yapılmaktadır. Öyle ki yapılan birçok çalışmada örgüt kültürü ile örgütün başarısı arasında doğrudan bir ilişki kurulmaktadır. Ayrıca örgütleri içinde bulundukları toplumun kültüründen bağımsız olarak düşünmek çok zordur. Çünkü bir toplumun sahip olduğu kültürel özellikler ve değerler, örgüt, yönetim ve yönetici kavramlarının algılanışını olduğu kadar yönetim biçimini, yönetim süreç ve uygulamalarını da etkilemektedir. Örgütü oluşturan insanlar, sahip oldukları kültürü o örgüte getirmektedirler. Dolayısı ile örgütler, hem içinde bulundukları toplumun kültüründen etkilenmekte hem de kendi içindeki bireyler aracılığı ile toplumun kültürünü etkilemektedir.

Aslında örgütlerin kültür, değer, inanç, norm, dil ve benzeri kavramlar ile ilişkilerinin kurulması sadece bir akım ya da popüler bir durum değildir. Örgütlerin sosyal gerçekliğinin bu kavramlar ile açıklanmak istenmesinin ardında paradigmatik bir dönüşümün olduğu söylenebilir. Genelde bilim özelde de yönetim ve eğitim yönetimi alanlarında egemen paradigma olan pozitivizme karşı yapılan eleştiriler bu tip çalışmaların artmasında rol oynamıştır. Çünkü pozitivist bakış açısı gerçeğin evrensel ve tek, ayrıca bu gerçeğin değerden bağımsız olduğuna vurgu yapmaktadır. Teorik temellerini doğa bilimlerinden alan ve eğitim yönetiminde de egemen bir paradigma olan pozitivizm; araştırmacıların gerçeği değerden, teoriği pratikten, rasyonelliği sağduyudan ayrı tutması zorunluluğunu temel ilke olarak benimsemiştir. $\mathrm{Bu}$ anlayış, gerek sosyal bilimlerde gerek eğitim yönetiminde, bir süreden beri sorgulanmaktadır (Sargut, 1994; Şimşek, 1997; Şişman, 1998; Balc1, 2003; Turan, 2004).

Kültüre yönelik bu yoğun ilgiden eğitim örgütleri de gereken pay1 almıştır. Eğitim örgütleri ile ilgili yapılan araştırmalarda (Şişman, 1994; İpek, 1999; Terzi, 2000; Erdem ve İşbaş1, 2001), eğitim örgütlerinin birer işletmeden daha çok kültürel topluluklar olarak görülmesi gerektiği vurgulanmaktadır. Ayrıca eğitim örgütlerinin, bütünüyle pozitivist ve rasyonel bakış açısıyla çözümlenmesi de mümkün görünmemektedir. Sergiovanni ve Corbally'e (1986) göre örgütler, rasyonel özelliklerden daha çok rasyonel olmayan özellikler yani kültürel özellikler göstermektedir. Bundan dolayı örgüt çözümlemelerinde kültürel özelliklere esas alınmalıdır. Okulların kültürel özelliklerinin belirlenmesi eğitim örgütlerinin özelliklerine daha uygun düşmektedir. Çünkü eğitim örgütleri özellikleri itibari ile insanlarla uğraşan örgütlerdir. Eğitim örgütlerinde bulunan bireyler yoğun bir etkileşim yaşamakta ve bu durum örgütün her türlü özelliğine 
yansımaktadır. $\mathrm{Bu}$ durumun etkilediği özelliklerden birisi de eğitim örgütlerinin örgüt kültürüdür.

Eğitim örgütlerinde örgüt kültürünün, eğitim hizmetini verenlerin, eğitim hizmetini alanların ve örgütteki idari işgörenlerin alt kültürlerinin karşıllklı etkileşiminin bir ürünü olduğu söylenilebilir. $\mathrm{Bu}$ yönden bakıldığında eğitim örgütlerindeki öğrencilerin örgüt kültürüne ilişkin algılarının belirlenmesi önem taşımaktadır. Bu önemi belirleyen belki de en önemli etken, bu belirlemenin öğrencilerin yetiştirilme sürecine yapacağ 1 katkıdır.

\section{KÜLTÜR VE ÖRGÜT KÜLTÜRÜ KAVRAMI}

Kültür, sosyal bilimlerdeki birçok kavramda olduğu gibi, tanımlanması zor bir kavramdır. Bundan dolayı da kültürle ilgili birçok tanıma ulaşmak mümkündür. Kültür, insan etkileşimini geliştiren sosyal tecrübenin bir sonucudur (Kreps, 1986, 134). Kültür, hayata anlam veren inançlar, değerler ve bilgiyi eylemle birleştiren entelektüel bir çatıdır (Bates, 1992). Kültür, bir toplumun, bilgi, ideoloji, değer, hukuk ve günlük ritüel sistemine yansıyan gelişme modelidir (Morgan, 1998).

Kültürle ilgili yapılan tanımların, bu kavramın içine aldığı tüm unsurları kapsaması olanaklı değildir. Biyoloji, güzel sanatlar, felsefe, tarih, antropoloji, sosyoloji ve daha birçok bilim dalında kültür tanımları yapılmaktadır (Şişman, 1994). Kültür kavramı günlük dilde de çok yaygın olarak kullanılan birçok farklı anlamın yüklendiği bir kavramdır. Kültür kavramına her bilim adamı, yazar ya da araştırmacı hatta birey farklı anlamlar yüklemekte ve buna göre tanımlamalar yapmaktadır. Kültür kavramının tanımlanmasındaki bu farklılıklar örgüt kültürü kavramının tanımlanmasında da karşımıza çıkmaktadır.

Örgüt kültürü, bir grubun üyeleri tarafindan paylaşılan inanç, sayıltı ve değerler sistemi, grup yaşantısının öğrenilen sonuçları, herhangi bir grubun kendi içinde bütünleşme ve dış çevreye uyum sorunlarını çözmek amacıyla öğrenme süreci içinde geliştirmiş̧ olduğu sayılttlar örüntüsüdür (Schein, 1992).

Örgüt kültürü, örgütü diğer örgütlerden ayıran, örgüt üyeleri tarafından paylaşılan bir anlamlar sistemini ifade etmektedir (Robbins, 1994, 299). Örgüt kültürü sadece örgüte ilişkin bir betimleme değildir, örgütün kendi içindeki betimlemesidir (Steinhoff ve Owens, 1989). Örgüt kültürü, örgütün ideolojisi ya da örgütü diğerlerinden ayıran inanç ve geleneklerdir (Hoy ve Miskel, 1996). Örgüt kültürü, örgüt üyelerine belirli değer ve inançları ileten sembol, seremoni ve mitlerdir (Ouchi, 1981 Akt: Hoy ve Miskel, 1996; Hoy, Tarter ve Kottkamp, 1991). Örgüt kültürü, paylaşılmış felsefe, ideolojiler, 
inançlar, duygular, varsayımlar, beklentiler, tutumlar, normlar ve değerler olarak tanımlanabilir (Lunenburg ve Ornstein, 2000).

Örgüt kültürü ile ilgili tanımlardaki bu farklılıkların, kültür kavramının tanımlanmasındaki farklılıklardan kaynakladığı söylenilebilir. Bunun sebebi, örgütler üzerinde yapılan çalışmalarda kültürün farklı tanımlaması, yapılan çalışmaların amaçları bakımında birbirinden farklılıklar göstermesidir. Ayrıca bunda araştırmacıların farklı paradigmalara sahip olmalarının da (Alvesson, 1993 Akt: Gizir, 1993) etkisi olduğu söylenilebilir. Çünkü araştırmacıların pozitivist paradigmadan yorumsamacı ve postmodern paradigmalara kadar uzanan çeşitli paradigmalara sahip olmaları kültüre yönelik farklı bakış açılarını ve her farklı bakış açısı da sonuçta farklı bir örgüt kültürü tanımı da ortaya çıkarmıştır. Baker'a (1992) göre ise örgüt kültürünü tanımlamanın zorluğunun temel sebeplerinden birisi, kavramın "zor ve örtük" bir kavram olmasıdır.

Yukarıdaki tanımlarda da görüldüğü gibi örgüt kültürü ile ilgili farklı tanımlar olsa da, yapılan tanımlarda genellikle değerler, normlar, semboller, davranışlar, duygular, sayıltılar, inançlar, törenler, efsaneler gibi kavramların kullanıldığı söylenebilir. Aslında bu kavramların bizi örgüt kültürünün öğelerine götürdüğü de söylenilebilir. Örgüt kültürünün öğeleri ile ilgili olarak da farklı sınıflamalar da bulunmaktadır. Ancak burada Schein (1992) tarafindan yapılan sınıflamaya yer verilmiştir. Çünkü Plath'a (1987) göre Schein tarafından yapılan bu sınıflandırma hem işletmelerde başarıyla kullanılmaktadır hem de eğitim örgütlerinin örgüt kültürünü açıklamak için de başarıyla kullanılabilmektedir (Akt: Şişman, 1994). Bu sınıflamaya göre örgüt kültürü; artifaktlar, değerler ve temel sayıltılardan oluşmaktadır.

Artifaktlar. Artifaktlar, daha çok kültürün gözle görülen yönünü oluşturmaktadır. Buluşlar, teknoloji, sanat (mitler, semboller, hikâyeler, efsaneler) ve görülebilen, duyulabilen davranış örüntüleridir (Schein, 1992; 1984). Bu anlamda artifaktlar, insanların işitebileceği, görebileceği ve hissedebileceği somut örgütsel unsurlardır (Bakan, Büyükbeşe, ve Bedestenci, 2004).

Değerler. Değerler, örgüt üyelerinin, olay, durum ve davranışları değerlendirmede, yargılamada benimsemiş oldukları ölçütlerdir (Schein, 1992; 1984).

Temel sayıltılar. Sayıltılar, örgüt üyelerinin, çevreyle ilişkiler, gerçek, zaman, mekân ve insan eylemleri ve insan ilişkilerinin doğasıyla ilgili olarak paylaştıkları temel inançlardır (Schein, 1992; 1984). Açıklamalar 1şı̆̆ında, örgüt üyelerinin sayıltılar konusunda aralarında tam bir uzlaşma varsa, bu grubun uyumlu bir grup olduğu söylenebilir (Bakan, Büyükbeşe, ve Bedestenci, 2004). 
Örgüt kültürü, birçok alt kültürden meydana gelmektedir. Bu alt kültürlerin etkisi ve gücü değişebilmektedir. Alt kültürler, kişilerin karşılaştıkları ortak problemler, durumlar ve deneyimlerin etkileşimi ile oluşur (Erdem, 1996). Alt kültürlerin örgüt kültürüne ilişkin görüşleri büyük önem taşımaktadır. Çünkü alt kültürlerin örgüt kültürüne destek olmaları gerekmektedir. Eğer alt kültürler örgüt kültürü ile ilgili olumsuz görüşlere sahip iseler, bu görüşler örgütü zayıflatabilir. Eğitim örgütlerindeki alt kültürlerden birisi de öğrenci alt kültürüdür. Öğrencilerin örgüt kültürüne ilişkin görüşlerinin belirlenmesi, eğitim öğretim etkinliklerinin geliştirilmesi açısından büyük öneme sahiptir. Çünkü eğitim örgütlerindeki örgüt kültürünün bir kısmını, örgütün resmi olarak açıklanmış kuralları, düzenlemeleri, amaçları, gelenekleri ve sembolleri oluştururken, diğer kısmını ise öğrencilere kazandırılmak istenen akademik disiplin kültürünün öngördügüü tutumlar oluşturmaktadır (Enoch, 1989).

$\mathrm{Bu}$ araştırmada örgüt kültürü ve fakülte kültürü kavramları eş anlamlı olarak kullanılmıştır. Araştırmada fakülte kültürü kavramı yukarıda da sıralandığ 1 gibi okulun resmi olarak açıklanmış kurallarının, düzenlemelerinin, amaçlarının, geleneklerinin, sembollerinin, kazandırılmak istenen akademik disiplin kültürünün bir bileşimi olarak algılanmıştır. Çünkü bir araştırmada kültürü bütün yönleri ile açıklamak oldukça zordur. Ancak önemli olan örgüt kültürünün ne olduğundan daha çok, bir alt kültür olarak öğrencilerin fakülte kültürünü (örgüt kültürünü) nasıl algıladıkları önemlidir. Çünkü eğitim örgütleri kendilerine özgü özellikleri itibari ile yoğun etkileşimlerin yaşandığı örgütlerdir. Eğitim örgütlerinin uğraşı alanlarının doğrudan doğruya insan olması, bu önemi daha da artırmaktadır.

Örgüt kültürü literatüründe eğitim örgütleri kültürü, okul kültürü adıyla çok sayıda çalışmanın konusunu oluşturmaktadır. Okul kültürü, paylaşılan değerler, inançlar, ortak bir misyon, kahramanlar, adetler, gelenekler ve bir tarihten oluşmaktadır (Erdem ve İşbaş1, 2001). Eğitim örgütlerinin önemli alt kültürleri, yöneticiler, eğiticiler ve öğrencilerdir. Buna göre bu araştırmanın amacı; Ankara Üniversitesi Eğitim Bilimleri Fakültesi son sınıf öğrencilerinin örgüt (fakülte) kültürüne ilişkin algılarını belirlemektir. Araştırmanın alt amaçları ise şunlardır:

1. Ankara Üniversitesi Eğitim Bilimleri Fakültesi son sınıf öğrencilerinin fakülte kültürüne ilişkin algıları cinsiyet göre değişmekte midir?

2. Ankara Üniversitesi Eğitim Bilimleri Fakültesi son sınıf öğrencilerinin fakülte kültürüne ilişkin algıları öğrenim gördükleri bölümlere göre değişmekte midir? 


\section{YÖNTEM}

Üniversite öğrencilerinin fakülte kültürüne ilişkin algılarını belirlemeyi amaçlayan bu araştırma tarama modelindedir. Tarama modeli araştırmalar, geçmişte ya da halen varolan bir durumu varolduğu şekliyle betimlemeyi amaçlayan bir araştırma yaklaşımıdır (Karasar, 1995). Araştırmanın çalışma grubu Ankara Üniversitesi Eğitim Bilimleri Fakültesi’nde öğrenim gören 275 dördüncü (son) sınıf öğrencisinden oluşmaktadır. 2004-2005 öğretim yılında Eğitim Bilimleri Fakültesi’nde öğrenim gören son sınıf öğrencilerinin bölümlere göre dağılımı ve bu öğrencilerden araştırmaya katılanların sayıları Çizelge 1'de yer almaktadır.

Çizelge 1. Ankara Üniversitesi Eğitim Bilimleri Fakültesi Son Sınıf Öğrencilerinin ve Araştırmaya Katılan Öğrencilerin Dağılımı (2004-2005)

\begin{tabular}{lcccc}
\hline \multicolumn{1}{c}{ Bölüm } & $\begin{array}{c}\text { Son Sınıf } \\
\text { Öğrencisi } \\
\text { Sayısı }\end{array}$ & $\begin{array}{c}\text { Son Sınıf } \\
\text { Öğrencisi } \\
\text { Yüzdesi } \\
(\%)\end{array}$ & $\begin{array}{c}\text { Araştırmaya } \\
\text { Katılan Son } \\
\text { Öğrencilerin } \\
\text { Sayısı (N) }\end{array}$ & $\begin{array}{c}\text { Araştırmaya } \\
\text { Katılan Son }\end{array}$ \\
$\begin{array}{lcccc}\text { Ögrencilerin } \\
\text { Yüzdesi (\%) }\end{array}$ \\
\hline $\begin{array}{l}\text { Rehberlik ve Psikolojik } \\
\text { Danışmanlık }\end{array}$ & 70 & 17,7 & 42 & 15,3 \\
$\begin{array}{l}\text { Bilgisayar ve Öğretim } \\
\text { Teknolojileri Eğitimi }\end{array}$ & 54 & 13,6 & 39 & 14,2 \\
(BÖTE) & & & & \\
$\begin{array}{l}\text { Okul Öncesi Öğretmenliği } \\
\text { Sinıf Öğretmenliği }\end{array}$ & 56 & 14,1 & 50 & 18,2 \\
Sosyal Bilgiler Öğretmenliği & 116 & 29,3 & 77 & 28,0 \\
Zihin Engelliler & 59 & 14,9 & 43 & 15,6 \\
Öğretmenliği & 41 & 10,4 & 24 & 8,7 \\
TOPLAM & 398 & 100 & 275 & 100 \\
\hline
\end{tabular}

Araştırmada sadece son sınıf öğrencilerine veri toplama aracı uygulanmıştır. Bunun sebebi, son sınıf öğrencilerinin, fakültedeki örgüt kültürünü algılamak için gerekli olan azami süreyi fakültede geçirmiş olmalarıdır. Araştırmaya, fakültede dört yıldan fazla eğitim gören öğrenciler dâhil edilmemiştir. Bunu sebebi de bu öğrencilerin fakülteye karşı olumsuz bir tavır geliştirebilmeleri ihtimalidir. Araştırmaya katılan öğrencilerin cinsiyete ve yaşa göre dağılımları Çizelge 2'de görülmektedir.

Çizelge 2'de de görüldüğü gibi araştırmaya katılan son sınıf öğrencilerinin \% 65,8'i kız, \% 34,2'si erkek öğrencidir. Araştırmaya katılan öğrencilerin yaşları, 20-23, 24 ve yukarısı olarak iki grup halinde gruplandığında; 20-23 yaş grubunda 216 (\% 78.5) kişi, 24 ve yukarısı grubunda 59 (\% 21.5) kişi olduğu bulunmuştur. 
Çizelge 2. Araştırmaya Katılan Öğrencilerin Cinsiyet ve Yaş Değiş̧kenlerine Göre

\begin{tabular}{|c|c|c|c|}
\hline \multicolumn{4}{|c|}{ Dağılımı } \\
\hline & & $\mathrm{N}$ & $\%$ \\
\hline \multirow{2}{*}{ Cinsiyet } & Erkek & 94 & 34,2 \\
\hline & $\mathrm{K} 1 \mathrm{z}$ & 181 & 65,8 \\
\hline \multirow{10}{*}{ Yaş } & 20 & 2 & 0,7 \\
\hline & 21 & 60 & 21,8 \\
\hline & 22 & 94 & 34,2 \\
\hline & 23 & 60 & 21,8 \\
\hline & 24 & 32 & 11,6 \\
\hline & 25 & 15 & 5,5 \\
\hline & 26 & 4 & 1,5 \\
\hline & 27 & 6 & 2,2 \\
\hline & 28 & 1 & 0,4 \\
\hline & 34 & 1 & 0,4 \\
\hline
\end{tabular}

Araştırmada kullanılan ölçek, Erdem ve İşbaşı (2001) tarafından geliştirilmiştir. Orijinal ölçeğin, faktör analizi sonucunda, beş alt boyuttan oluştuğu belirlenmiştir. Bu alt boyutlar, "Aidiyet", "Semboller", "Güç Mesafesi", "İletişim / İlişki" ve "Örgütsel Yapı / Etkinlik" alt boyutlarıdır. Ölçeğin güvenirlik katsayısı ise $.89^{\prime}$ dur. $\mathrm{Bu}$ çalışma için ölçekteki maddelerden bazılarında değişiklik yapıldığından ölçek üzerinde tekrar faktör analizi ve güvenirlik analizi yapılmıştır. Yapılan bu analizde ölçeğin, özdeğeri 1'den yüksek olan 8 alt boyutu olduğu görülmüştür. Ancak yapılan incelemeler sonucunda bu alt boyutlardan bazılarında tek madde yer aldığı, bazılarında ise madde yer almadığı ve ölçeğin aslında tek boyutlu olduğu görülmüş ve buna göre yeniden, tek boyutlu olarak faktör analizi yapılmıştır. Yapılan analiz sonucunda faktör yükü değeri 0.40 ' 1 altında olan dört madde ölçekten çıkarılmıştır. Buna göre faktörün özdeğeri, 8,737, açıkladığ1 varyans oranı ise \% 28,18 olarak hesaplanmıştır. Daha sonra güvenirlik analizi yapılmıştır. Yapılan güvenirlik analizi sonuçlarına göre ölçeğin Alpha Güvenirlik Katsayısı 0,89 olarak hesaplanmıştır.

Araştırmada, araştırmanın amacına uygun olarak veriler üzerinde frekans, yüzde, t-testi, Kruskal Wallis ve Mann Whitney U-testi analizleri yapılmışır. Frekans ve yüzde katılımcıların kişisel bilgilerini ve ölçekte yer alan maddelere ilişskin görüşlerini değerlendirmeye yönelik olarak, t-testi araştırmaya katılan öğrencilerin fakülte kültürüne ilişkin algılarının cinsiyete göre değişip değişmediğinin belirlenmesi için, Kruskal Wallis analizi araştırmaya katılan öğrencilerin fakülte kültürüne ilişkin algılarının öğrenim gördükleri bölümlere göre değişip değişmediğinin belirlenmesi için kullanılmıştır. Yapılan analizlerde öğrenim görülen bölümler arasındaki fark anlamlı olduğu için, hangi gruplar arasındaki farkın anlamlı olduğunun belirlenmesi için bütün bölümler kendi aralarında karşılaştırılmıştır. Bunun ile ilgili olarak da Mann Whitney U-Testi analizi yapılmıştır. 


\section{BULGULAR}

Araştırmaya katılan öğrencilerin, ölçekte yer alan maddelere verdikleri cevapların frekans ve yüzdeleri Ek 1'de yer almaktadır.

Ek 1'de de görüldüğü gibi araştırmaya katılan öğrencilerin verdikleri cevaplara göre, "diğer üniversitelerin eğitim fakültelerinin aynı bölümündeki öğrenciler ile rekabette kendimi şanslı görüyorum" (\% 65,5), "fakültenin dışarıda (kampusta, kentte) olumlu bir imajı vardır" (\% 57,5), "fakültenin araştırma görevlileri öğrencilere içtenlikle yardımcı olurlar” (\% 55,6), "öğretim üyelerinin öğrencilere yaklaşımı insancıldır" (\% 54,1), "bu üniversitede Eğitim Bilimleri Fakültesi öğrencisi olmak bir ayrıcalıktır” (\% 53,1 ) en olumlu algılamaları anlatan ifadelerdir. "Fakültenin geçmişine ilişkin anılar, öyküler, olaylar eski öğrenciler tarafından yenilere aktarılır" (\% 60,8), "fakültenin fiziki mekânları diğer fakültelere göre farklı ve özgündür" (\% 56,0), "fakültemizde uygulamalar açısından bölümler arasında yüksek uyum vardır" (\% 56,0), "farklı sınıflardaki öğrencileri arasındaki iletişim güçlüdür" (\% 52,3), "fakültenin yöneticileri sorunların giderilmesinde başarılıdır" (\% 51,3) ifadeleri ise en olumsuz ifadelerdir.

Bu cevaplar cevap skalasına göre tek tek değerlendirildiğinde en yüksek "tamamen katılıyorum" cevabını "diğer üniversitelerin eğitim fakültelerinin aynı bölümündeki öğrenciler ile rekabette kendimi şanslı görüyorum" (78) \% 28,4 'lük bir oranla vermişlerdir.

Öğrenciler "katıllyorum" cevabını en yüksek oranda, \% 48,5 ile iki ifadeye vermiştir. Bu ifadeler, "fakültenin araştırma görevlileri öğrencilere içtenlikle yardımcı olurlar" ve "öğretim üyelerinin öğrencilere yaklaşımı insancıldır" ifadeleridir. Bu ifadelere 128 öğrenci "katılıyorum" cevabını vermiştir.

Öğrenciler, "kararsızım" cevabını ise en yüksek oranda \% 42,5 ile "fakültenin öğretim elemanları kendi aralarında işbirliği ve dayanışma içindedirler" ifadesine vermişlerdir. Bu soruya 117 öğrenci "kararsızım" cevabını vermiştir.

Öğrenciler verdikleri "katılmıyorum" cevabı da iki farklı ifadede en yüksek orana $(\% 36,4)$ sahiptir. Bu ifadeler; "fakültenin geçmişine ilişkin

anılar, öyküler, olaylar eski öğrenciler tarafından yenilere aktarılır" ve "öğrenciler, fakültedeki uygulamalara yönelik sorunlarını veya düşüncelerini yöneticilere yeterli düzeyde aktarabilirler" ifadeleridir. Bu ifadelere 100 öğrenci "katılmıyorum" cevabını vermiştir.

Öğrenciler, "kesinlikle katılmıyorum" cevabını ise "fakültenin fiziki mekânları diğer fakültelere göre farklı ve özgündür" ifadesine vermişlerdir. $\mathrm{Bu}$ ifadeye 72 (\% 26,2) öğrenci "kesinlikle katılmıyorum" cevabını vermiştir. 
Araştırmaya katılan öğrencilerin fakülte kültürüne ilişkin algılarının cinsiyetlerine ve öğrenim gördükleri bölümlere göre farklılık gösterip göstermediği ile ilgili analizler t-testi ve Kruskal Wallis analizleri ile test edilmiştir. Cinsiyet değişkenine göre yapılan t-testi analizi sonuçları Çizelge 3 'te yer almaktadır.

Çizelge 3. Araştırmaya Katılan Öğrencilerin Fakülte Kültürüne İlişkin Algılarının Cinsiyete Göre t-testi Sonuçları

\begin{tabular}{lcccccc}
\hline Cinsiyet & $\mathrm{N}$ & $\overline{\mathrm{X}}$ & $\mathrm{S}$ & $\mathrm{sd}$ & $\mathrm{t}$ & $\mathrm{p}$ \\
\hline Kiz & 181 & 80,57 & 15,73 & 150,94 & 1,950 & 0,053 \\
Erkek & 94 & 85,29 & 20,56 & & & \\
\hline
\end{tabular}

Çizelge 3'te de görüldüğü gibi araştırmaya katılan öğrencilerin fakülte kültürüne ilişkin algıları cinsiyete göre anlamlı bir farklılık göstermemektedir $\left[\mathrm{t}_{(150,94)}=1,950, \mathrm{p}>.05\right]$. Buna göre fakülte kültürüne ilişkin algılar ile cinsiyet arasında anlamlı bir ilişki yoktur denilebilir. Buradan çıkan sonuca göre, fakültede örgüt kültürünü oluşturan unsurlardan kız ve erkek öğrencilerin aynı derecede etkilendikleri söylenebilir. Öğrencilerin fakülte kültürüne ilişkin algıları arasında cinsiyete göre fark bulunmamıştır. Acaba bu durum öğrencilerin öğrenim gördükleri bölümler için de geçerli midir? $\mathrm{Bu}$ amaçla, öğrencilerin fakülte kültürüne ilişkin algılarının öğrenim gördükleri bölüme göre değişip değişmediğini belirlemek için Kruskal Wallis analizi yapılmıştır. Burada bu analizin seçilmesinin nedeni öğrencilerin öğrenim gördükleri bölümlere ilişkin dağılımın normal olmamasıdır. Buna göre yapılmış olan Kruskal Wallis analizi sonuçları Çizelge 4'te yer almaktadır.

Çizelge 4. Araştırmaya Katılan Öğrencilerin Fakülte Kültürüne İlişkin Algılarının Öğrenim Gördükleri Bölümlere Göre Kruskal Wallis Testi Sonuçları

\begin{tabular}{lccccc}
\multicolumn{1}{c}{ Bölüm } & $\mathrm{N}$ & $\begin{array}{c}\text { Sira } \\
\text { Ortalaması }\end{array}$ & sd & $\chi^{2}$ & $\mathrm{p}$ \\
\hline BÖTE & 39 & 112,35 & 5 & 17,96 &, 003 \\
Sınıf Öğretmenliği & 77 & 122,79 & & & \\
Okul Öncesi Öğretmenliği & 50 & 138,60 & & & \\
Rehberlik ve Psikolojik & 42 & 144,98 & & & \\
Danışmanlık & & & & \\
Sosyal Bilgiler & 43 & 15,71 & & \\
Öğretmenliği & & & & \\
Zihin Engelliler & 24 & 186,90 & & \\
Öğretmenliği & & & & \\
\hline
\end{tabular}


Çizelge 4'te de görüldüğü gibi analiz sonuçlarına göre; araştırmaya katılan öğrencilerin fakülte kültürüne ilişkin algıları, öğrenim gördükleri bölümlere göre anlamlı bir şekilde farklılaşmaktadır $\left[\chi^{2}(5)=17,96, p<\right.$ $.01]$. $\mathrm{Bu}$ bulgu, öğrencilerin öğrenim gördükleri bölümlerin, öğrencilerin fakülte kültürüne ilişkin algılarını farklı şekilde etkilediğini göstermektedir. Bölümlerin sıra ortalamaları dikkate alındığında, en yüksek ortalamaya “Zihinsel Engelliler Öğretmenliği” bölümünde öğrenim görenlerin, en düşük ortalamaya ise "Bilgisayar ve Öğretim Teknolojileri Eğitimi" bölümünde öğrenim görenlerin sahip oldukları görülmektedir. Burada yapılan analizler sonucunda bölümler arasındaki fark anlamlı olduğu için, hangi gruplar arasındaki farkın anlamlı olduğunun belirlenmesi gerekmektedir. Bunun için bütün bölümler kendi aralarında karşılaş̧ırılmıştır. Bunun ile ilgili Mann Whitney U-Testi analizi sonuçları Çizelge 5 'te yer almaktadır.

Çizelge 5. Araştırmaya Katılan Öğrencilerin Fakülte Kültürüne İlişkin Algılarının Öğrenim Gördükleri Bölümlere Göre U-Testi Sonuçları

\begin{tabular}{|c|c|c|c|c|c|}
\hline Bölüm & $\mathrm{N}$ & $\begin{array}{c}\text { Sira } \\
\text { Ortalamas1 }\end{array}$ & $\begin{array}{c}\text { Sira } \\
\text { Toplamı }\end{array}$ & $\mathrm{U}$ & $\mathrm{p}$ \\
\hline $\begin{array}{l}\text { Rehberlik ve Psikolojik } \\
\text { Danışmanlık }\end{array}$ & 42 & 29,25 & 1228,50 & 325,5 & .017 \\
\hline $\begin{array}{l}\text { Zihin Engelliler } \\
\text { Öğretmenliği }\end{array}$ & 24 & 40,94 & 982,50 & & \\
\hline Sınıf Öğretmenliği & 77 & 45,47 & 3501,5 & 498,5 & .001 \\
\hline $\begin{array}{l}\text { Zihin Engelliler } \\
\text { Öğretmenliği }\end{array}$ & 24 & 68,73 & 1649,5 & & \\
\hline Sosyal Bilgiler Öğretmenliği & 43 & 47,15 & 2027,5 & 595,5 & .024 \\
\hline ВÖTE & 39 & 35,27 & 1375,5 & & \\
\hline BÖTE & 39 & 26,19 & 1021,50 & 241,5 & .001 \\
\hline $\begin{array}{l}\text { Zihin Engelliler } \\
\text { Öğretmenliği }\end{array}$ & 24 & 41,44 & 994,5 & & \\
\hline $\begin{array}{l}\text { Zihin Engelliler } \\
\text { Öğretmenliği }\end{array}$ & 24 & 46,38 & 1113,0 & 387,0 & .014 \\
\hline Okul Öncesi Öğretmenliği & 50 & 33,24 & 1662,0 & & \\
\hline
\end{tabular}

Çizelge 5'te de görüldüğ̈̈ gibi araştırmaya katılan öğrencilerden "Rehberlik ve Psikolojik Danışmanlık" bölümünde öğrenim gören öğrenciler ile "Zihin Engelliler Öğretmenliği” bölümünde öğrenim gören öğrencilerin fakülte kültürüne ilişkin algıları arasında anlamlı bir fark olduğu bulunmuştur $(U=325,5, \mathrm{p}<.05)$. Sira ortalamaları dikkate alındığında, "Zihin Engelliler Öğretmenliği” bölümünde öğrenim gören öğrencilerin 
fakülte kültürüne ilişkin algılarının "Rehberlik ve Psikolojik Danışmanlık" bölümünde öğrenim gören öğrencilere göre daha olumlu olduğu görülmektedir. "Sınıf Öğretmenliği” bölümünde öğrenim gören öğrenciler ile "Zihin Engelliler Öğretmenliği” bölümünde öğrenim gören öğrencilerin fakülte kültürüne ilişkin algıları arasında da anlamlı bir fark olduğu bulunmuştur $(\mathrm{U}=498,5, \mathrm{p}<.05)$. Sıra ortalamaları dikkate alındığında ise, "Zihin Engelliler Öğretmenliği” bölümünde öğrenim gören öğrencilerin fakülte kültürüne ilişkin algılarının "Sınıf Öğretmenliğì" bölümünde öğrenim gören öğrencilere göre daha olumlu olduğu görülmektedir.

"Sosyal Bilgiler Öğretmenliği” bölümünde öğrenim gören öğrenciler ile "Bilgisayar ve Öğretim Teknolojileri Eğitimi” bölümünde öğrenim gören öğrencilerin fakülte kültürüne ilişkin algıları arasında anlamlı bir fark bulunmuştur $(\mathrm{U}=595,5, \mathrm{p}<.05)$. Sira ortalamaları dikkate alındığında ise, "Sosyal Bilgiler Öğretmenliği” bölümünde öğrenim gören öğrencilerin fakülte kültürüne ilişkin algılarının "Bilgisayar ve Öğretim Teknolojileri Eğitimi” bölümünde öğrenim gören öğrencilere göre daha olumlu olduğu görülmektedir.

"Bilgisayar ve Öğretim Teknolojileri Eğitimi” bölümünde öğrenim gören ögrrenciler ile "Zihin Engelliler Öğretmenliği” bölümünde öğrenim gören öğrencilerin fakülte kültürüne ilişkin algıları arasında anlamlı bir fark bulunmuştur $(\mathrm{U}=241,5, \mathrm{p}<.05)$. Sira ortalamaları dikkate alındığında ise, "Zihinsel Engelliler Öğretmenliğì" bölümünde öğrenim gören öğrencilerin fakülte kültürüne ilişkin algılarının "Bilgisayar ve Öğretim Teknolojileri Eğitimi” bölümünde öğrenim gören öğrencilere göre daha olumlu olduğu görülmektedir.

"Zihin Engelliler Öğretmenliğì" bölümünde öğrenim gören öğrenciler ile "Okul Öncesi Öğretmenliği” bölümünde öğrenim gören öğrencilerin fakülte kültürüne ilişkin algıları arasında anlamlı bir fark bulunmuştur $(U=$ $387,5, \mathrm{p}<.05)$. Sira ortalamaları dikkate alındığında ise, "Zihinsel Engelliler Öğretmenliği”" bölümünde öğrenim gören öğrencilerin fakülte kültürüne ilişkin algılarının "Okul Öncesi Öğretmenliğgi” bölümünde öğrenim gören öğrencilere göre daha olumlu olduğu görülmektedir.

\section{TARTIŞMA}

Araştırmaya katılan öğrencilerin verdikleri cevaplara göre, "diğer üniversitelerin eğitim fakültelerinin aynı bölümündeki öğrenciler ile rekabette kendimi şanslı görüyorum", "fakültenin dışarıda (kampusta, kentte) olumlu bir imajı vardır", "fakültenin araştırma görevlileri öğrencilere içtenlikle yardımcı olurlar", "öğretim üyelerinin öğrencilere yaklaşımı insancıldır" ve "bu üniversitede Eğitim Bilimleri Fakültesi öğrencisi olmak 
bir ayrıcalıktır" en olumlu algılamaları anlatan ifadelerdir. "Fakültenin geçmişine ilişkin anılar, öyküler, olaylar eski öğrenciler tarafından yenilere aktarılır", "fakültenin fiziki mekânları diğer fakültelere göre farklı ve özgündür", "fakültemizde uygulamalar açısından bölümler arasında yüksek uyum vardır", "farklı sınıf öğrencileri arsında iletişim güçlüdür" ve "fakültenin yöneticileri sorunların giderilmesinde başarılıdır" ifadeleri ise en olumsuz olarak görülen ifadelerdir.

Bu cevaplar cevap skalasına göre tek tek değerlendirildiğinde en yüksek "tamamen katıllyorum" cevabı "diğer üniversitelerin eğitim fakültelerinin aynı bölümündeki öğrenciler ile rekabette kendimi şanslı görüyorum" ifadesine, "katılıyorum" cevabını en yüksek oranda, "fakültenin araştırma görevlileri öğrencilere içtenlikle yardımcı olurlar" ve "öğretim üyelerinin öğrencilere yaklaşımı insancıldır" ifadelerine, "kararsızım" cevabını ise en yüksek oranda "fakültenin öğretim elemanları kendi aralarında işbirliği ve dayanışma içindedirler" ifadesine, "katılmıyorum" cevabı en yüksek oranda, "fakültenin geçmişine ilişkin anılar, öyküler, olaylar eski öğrenciler tarafindan yenilere aktarılır" ve "öğrenciler, fakültedeki uygulamalara yönelik sorunlarını veya düşüncelerini yöneticilere yeterli düzeyde aktarabilirler" ifadelerinde, "kesinlikle katılmıyorum" cevabını ise "fakültenin fiziki mekânları diğer fakültelere göre farklı ve özgündür" ifadesine vermişlerdir.

Erdem ve İşbaşı (2001) tarafindan yapılan araştırmada, en yüksek oranda olumlu cevaplar sırası ile fiziki mekânlar, törenler, öğretim üyelerinin insancıl yaklaşımı, öğretim üyelerinin iletişime açık olmaları, araştırma görevlilerinin ilgisi, İ.I..B.F. öğrencisi olma ayrıcalığı ifadelerine aittir. Olumsuz ifadeler ise, bölümler arası uyumun olmadığı, diğer bölümlerin işleyişinin bilinmediği, derslerin veriliş şeklinin beceri ve düşünceyi geliştirme özelliği olmadığı yönündeki ifadelerdir. Buna göre iki araştırmada ögrencilerin verdikleri cevaplar arasında paralellik yoktur.

Araştırmaya katılan öğrencilerin fakülte kültürüne ilişkin algıları cinsiyete göre anlamlı bir farklılık göstermemektedir. Bunun sebebi, öğrencilerin fakültedeki uygulamalara ilişkin olarak benzer bir bakış açısına sahip olmaları olabilir. Ya da fakülte kültürünü oluşturan unsurlardan kızlar ve erkekler aynı oranlarda etkilenmektedir.

Araştırmaya katılan öğrencilerin fakülte kültürüne ilişkin algıları, öğrenim gördükleri bölümlere göre anlamlı bir ş̧ekilde farklılaşmaktadır. Bölümler arasında yapılan Mann Whitney $U$ testi sonuçlarına göre; "Rehberlik ve Psikolojik Danışmanlık" ve "Zihin Engelliler Öğretmenliği”, "Sınıf Öğretmenliğì" ve "Zihin Engelliler Öğretmenliği”, "Sosyal Bilgiler Öğretmenliği” ve "BÖTE", "BÖTE" ve "Zihin Engelliler Öğretmenliğil, "Zihin Engelliler Öğretmenliği” ve "Okul Öncesi Öğretmenliği” bölümleri 
arasında anlamlı farklar bulunmuştur. Bölümler arasındaki bu farklılıkların sebebi, bölümlerde bulunan öğretim üyelerinin, araştırma görevlilerinin tutumlarından, ders işleme ve diğer konulara yaklaşımlarındaki farklılıklardan kaynaklanıyor olabilir. Ancak bu farklılık sadece bu değişkenler ile açıklanamayabilir. Çünkü fakültedeki birçok bölümün öğretim üyesi diğer bölümlerin derslerine girmektedir ve diğer bölümlerin öğrencileri ile de etkileşim halindedir. Bireylerin sahip oldukları kültürü içinde bulundukları örgütlere getirmeleri de, o örgütteki kültür algılarını etkilemektedir. Çünkü örgütleri ve bireyleri içinde bulundukları toplumlardan bağımsız düşünmek mümkün değildir.

Sonuç olarak öğrenciler, fakültenin geçmişine ilişkin anılar, öyküler ve olayların, eski öğrenciler tarafından yenilere aktarılmadığını, fakültenin fiziki mekânlarının diğer fakültelere göre farklı ve özgün olmadığını, fakültede uygulamalar açısından bölümler arasında yüksek uyum olmadığını, farklı sınıflardaki öğrencileri arasındaki iletişimin güçlü olmadığını, fakültenin yöneticilerinin sorunların giderilmesinde başarılı olmadığını belirtmişlerdir. Buna göre, öğrencilerin eksik gördükleri noktaların yöneticiler tarafından giderilmesi ya da bunları gidermeye yönelik çalışmalar yapmaları gerekmektedir. Öğrencilere fakültenin geçmişi ile ilgili bilgilerin verildiği toplantılar düzenlenebilir, fakültenin fiziki mekânlarının daha ilgi çekici ve hoş olması sağlanabilir, yapılan uygulamalarda bölümler arasında bir örneklik sağlanması için bölüm yöneticileri ve memurları bilgilendirilebilir, farklı sınıflardaki öğrencilerin iletişiminin artırılması için etkinlikler düzenlenebilir. Ayrıca en önemlisi, yöneticilerin sorunları çözmek için daha çok çalışması gerekmektedir.

Bundan sonraki araştırmalarda, araştırmacılara, bu tür çalışmaları bireylerin kültürel özelliklerini de dikkate alan araştırmalar yapmaları önerilebilir. Eğitim örgütlerinde yapılacak diğer araştırmalarda yönetici ve eğitici alt kültürlerini de dikkate alan ve bu alt kültürler arasında karşılaştırmalara yer veren araştırmalarda yapılabilir. Ayrıca bu tür çalışmalar, farklı fakülteler arasında, farklı sınıflar arasında, farklı bölümler arasında karşılaştırmalar yapılarak da gerçekleştirilebilir.

\section{KAYNAKLAR}

Baker, G. A. (1992). Creative cultures: toward a new paradigm. In G. A. Baker (Eds). Cultural Leadership. (pp. 1-16). Washington: Community College Pres.

Balcı, A. (2003). Eğitim Örgütlerine Yeni Bakış Açıları: Kuram-Araştırma İlişkisi II. Kuram ve Uygulamada Eğitim Yönetimi, 9 (33), 26-61. 
Bakan, İ. Büyükbeşe, T. ve Bedestenci, H. Ç. (2004). Örgüt Kültürü: Teorik ve Ampirik Yaklaşım. İstanbul: Aktüel Yayınları.

Bates, R. (1992). "The emerging culture of educational administration and what we can do about it". Paper presented at the National Conference of the Australian Council for Educational Administration. July, Darwin.

Enoch, Y. (1989). Change of values during socialization for a profession: an application of the marjinal man theory. Human Relations, 42 (3).

Erdem, F. (1996). İşletme Kültürü. Antalya: Akdeniz Üniversitesi Yayınları.

Erdem, F. ve İşbaşı, J. Ö. (2001). Eğitim Kurumlarında Örgüt Kültürü ve Öğrenci Alt Kültürünün Algılamaları. Akdeniz İI. B.F. Dergisi. (1), 3357.

Gizir, S. (2003). Örgüt Kültürü Çalışmalarında Yöntemsel Yaklaşımlar. Kuram ve Uygulamada Ĕ̈itim Yönetimi, 9 (35), 374-397.

Hoy, W. K. \& Miskel, C. G. (1996). Educational administration. New York: McGraw-Hill Inc.

Hoy, W. K., Tarter, C. J. \& Kottkamp, R. B. (1991). Open schools / healty schools. measuring organizational climate. USA: Sage Publications.

İpek, C. (1999). "Resmi Liseler ile Özel Liselerde Örgütsel Kültür ve Öğretmen-Öğrenci İlişkisi”. Yayınlanmamıș doktora tezi, Ankara Üniversitesi Sosyal Bilimler Enstitüsü, Ankara.

Karasar, N. (1995). Bilimsel Araştırma Yöntemi. Ankara: 3A Araştırma Eğitim Danışmanlık Ltd.

Kreps, G. F. (1986). Organizational communication. New York: Longman Inc.

Lunenburg, F. C. \& Ornstein, A. C. (2000). Educational administration. USA: Wadsworth Thomson Learning.

Morgan, G. (1998). Yönetim ve Örgüt Teorilerinde Metafor. (Çev: G. Bulut). İstanbul: MESS Yayınları.

Robbins, S. P. (1994). Örgütsel Davranışın Temelleri. (Çev: S. A. Öztürk). Eskişehir: Anadolu Üniversitesi Yayınları.

Sargut, S. (1994). Kültürlerarası Farklılaşma ve Yönetim. Ankara: Verso Yayıncilık.

Schein, E. H. (1984). Coming to a new awareness of organizational culture. Sloan Management Review, 25 (2), 3-16. 
Schein, E. H. (1992). Organizational culture and leadership. San Fransisco: Jossey Bass Publishers.

Sergiovanni, T. J. \& Corbally, J. E. (1986). Leadership and organizational culture. Chicago: University of Illinois Press.

Steinhoff, C. R. ve Owens, R. G. (1989). Toward a theory of organizational culture. Journal of Educational Administration. Vol. 27 No. 3, p. 6-16.

Şimşek, H. (1997). Pozitivizm Ötesi Paradigmatik Dönüşüm ve Eğitim Yönetiminde Kuram ve Uygulamada Yeni Yaklaşımlar. Kuram ve Uygulamada Eğitim Yönetimi, 3 (1), 97-109.

Şişman, M. (1994). Örgüt Kültürü. Eskişehir: Anadolu Üniversitesi Yayınları.

Şişman, M. (1998). Eğitim Yönetiminde Kuram ve Uygulamada Alternatif Paradigma ve Yaklaşımlar. Kuram ve Uygulamada Eğitim Yönetimi, 16, 395-422.

Terzi, A. R. (2000). Örgüt Kültürü. Ankara: Nobel Yayın Dağıtım.

Turan, S. (2004). Modernite ve Postmodernite Arasında Bir İnsan Bilimi Olarak Eğitim Yönetimi. Akdeniz Üniversitesi Ĕ̈itim Fakültesi Dergisi, $1(1), 1-8$. 
EK 1: Öğrencilerin Fakülte Kültürüne İlişkin Algılarının Dağılımı

\begin{tabular}{|c|c|c|c|c|c|}
\hline \multicolumn{6}{|c|}{$\begin{array}{l}\text { 1- Tamamen katılıyorum 2- Katılıyorum 3- Kararsızım 4- Katılmıyorum 5- } \\
\text { Kesinlikle katılmıyorum }\end{array}$} \\
\hline \multirow{2}{*}{ İfadeler } & 1 & 2 & 3 & 4 & 5 \\
\hline & $\begin{array}{l}\mathrm{F} / \\
\%\end{array}$ & $\begin{array}{l}\mathrm{F} / \\
\%\end{array}$ & $\begin{array}{l}\mathrm{F} / \\
\%\end{array}$ & $\begin{array}{l}\mathrm{F} / \\
\%\end{array}$ & $\begin{array}{l}\mathrm{F} / \\
\%\end{array}$ \\
\hline $\begin{array}{l}\text { 1. Fakültemizde uygulamalar açısından bölümler arasında } \\
\text { yüksek uyum vardır. }\end{array}$ & $\begin{array}{c}2 \\
0,7\end{array}$ & $\begin{array}{c}41 \\
14,9\end{array}$ & $\begin{array}{c}78 \\
28,4\end{array}$ & $\begin{array}{c}99 \\
36,0\end{array}$ & $\begin{array}{c}55 \\
20,0\end{array}$ \\
\hline $\begin{array}{l}\text { 2. Fakültenin yöneticileri sorunların giderilmesinde } \\
\text { başarılıdır. }\end{array}$ & - & $\begin{array}{c}46 \\
16,7\end{array}$ & $\begin{array}{c}88 \\
32,0\end{array}$ & $\begin{array}{c}91 \\
33,1\end{array}$ & $\begin{array}{c}50 \\
18,2\end{array}$ \\
\hline $\begin{array}{l}\text { 3. Fakültenin yöneticileri dışarıdan gelen etki ve baskılara } \\
\text { karşı fakülteyi korur. }\end{array}$ & $\begin{array}{c}7 \\
2,5\end{array}$ & $\begin{array}{c}68 \\
24,7 \\
\end{array}$ & $\begin{array}{c}93 \\
33,8 \\
\end{array}$ & $\begin{array}{c}69 \\
25,1 \\
\end{array}$ & $\begin{array}{c}38 \\
13,8 \\
\end{array}$ \\
\hline Öğretim üyeleri iletişime her zaman açıktır. & $\begin{array}{l}22 \\
8,0\end{array}$ & $\begin{array}{r}102 \\
37,1\end{array}$ & $\begin{array}{c}58 \\
21,1\end{array}$ & $\begin{array}{c}64 \\
23,3\end{array}$ & $\begin{array}{c}29 \\
10,5\end{array}$ \\
\hline $\begin{array}{l}\text { 5. Fakültenin eğitime yönelik hedefleri konusunda bilgi } \\
\text { sahibiyiz. }\end{array}$ & $\begin{array}{l}14 \\
5,1\end{array}$ & $\begin{array}{c}108 \\
39,8\end{array}$ & $\begin{array}{c}57 \\
20,7\end{array}$ & $\begin{array}{c}67 \\
24,4\end{array}$ & $\begin{array}{c}29 \\
10,5\end{array}$ \\
\hline $\begin{array}{ll}\text { 6. } & \text { Farklı sınıflardaki öğrenciler arasındaki iletişim } \\
\text { güçlüdür. }\end{array}$ & $\begin{array}{c}6 \\
2,2 \\
\end{array}$ & $\begin{array}{c}63 \\
22,9 \\
\end{array}$ & $\begin{array}{c}62 \\
22,5 \\
\end{array}$ & $\begin{array}{c}93 \\
33,8 \\
\end{array}$ & $\begin{array}{c}51 \\
18,5 \\
\end{array}$ \\
\hline 7. Öğretim üyelerinin öğrencilere yaklaşımı insancıldır. & $\begin{array}{l}21 \\
7,6\end{array}$ & $\begin{array}{r}128 \\
46,5\end{array}$ & $\begin{array}{c}62 \\
22,5\end{array}$ & $\begin{array}{c}47 \\
17,1\end{array}$ & $\begin{array}{l}17 \\
6,2\end{array}$ \\
\hline $\begin{array}{l}\text { 8. Derslerin veriliş şekli bilgi aktarmaktan çok düşünce ve } \\
\text { beceri geliştirici niteliktedir. }\end{array}$ & $\begin{array}{l}18 \\
6,5\end{array}$ & $\begin{array}{c}85 \\
30,9 \\
\end{array}$ & $\begin{array}{c}63 \\
22,9 \\
\end{array}$ & $\begin{array}{c}78 \\
28,4 \\
\end{array}$ & $\begin{array}{c}31 \\
11,3 \\
\end{array}$ \\
\hline $\begin{array}{l}\text { 9. Fakültenin dışarıda (kampusta, kentte) olumlu bir imajı } \\
\text { vardır. }\end{array}$ & $\begin{array}{c}42 \\
15,3\end{array}$ & $\begin{array}{l}116 \\
42,2\end{array}$ & $\begin{array}{c}65 \\
23,6\end{array}$ & $\begin{array}{c}31 \\
11,3\end{array}$ & $\begin{array}{l}21 \\
7,6\end{array}$ \\
\hline $\begin{array}{l}\text { 10. Fakültenin öğretim elemanları kendi aralarında işbirliği } \\
\text { ve dayanışma içindedirler. }\end{array}$ & $\begin{array}{l}10 \\
3,6\end{array}$ & $\begin{array}{c}93 \\
33,8 \\
\end{array}$ & $\begin{array}{l}117 \\
42,5 \\
\end{array}$ & $\begin{array}{c}43 \\
15,6 \\
\end{array}$ & $\begin{array}{l}12 \\
4,4\end{array}$ \\
\hline $\begin{array}{l}\text { 11. Fakülte yönetimi öğrencileri, yönetmeliklere ve } \\
\text { uygulamalara yönelik olarak zamanında ve doğru } \\
\text { bilgilendirir. }\end{array}$ & $\begin{array}{l}11 \\
4,0\end{array}$ & $\begin{array}{c}97 \\
35,3\end{array}$ & $\begin{array}{c}70 \\
25,5\end{array}$ & $\begin{array}{c}64 \\
23,3\end{array}$ & $\begin{array}{c}33 \\
12,0\end{array}$ \\
\hline 12. Öğretim üyeleri hatalara karşı toleranslı davranırlar. & $\begin{array}{c}9 \\
3,3\end{array}$ & $\begin{array}{c}92 \\
33,5\end{array}$ & $\begin{array}{c}96 \\
34,9\end{array}$ & $\begin{array}{c}55 \\
20,0\end{array}$ & $\begin{array}{l}23 \\
8,4\end{array}$ \\
\hline $\begin{array}{l}\text { 13. Öğrenciler hocalarını farklı sorunlarını iletecek kadar } \\
\text { yakın görürler. }\end{array}$ & $\begin{array}{l}16 \\
5,8\end{array}$ & $\begin{array}{c}66 \\
24,0\end{array}$ & $\begin{array}{c}77 \\
28,0\end{array}$ & $\begin{array}{c}82 \\
29,8\end{array}$ & $\begin{array}{c}34 \\
12,4\end{array}$ \\
\hline $\begin{array}{l}\text { 14. Öğrenciler, fakültedeki uygulamalara yönelik sorunlarını } \\
\text { veya düşüncelerini yöneticilere yeterli düzeyde } \\
\text { aktarabilirler. }\end{array}$ & 2,5 & $\begin{array}{c}62 \\
22,5\end{array}$ & $\begin{array}{c}78 \\
28,4\end{array}$ & $\begin{array}{l}100 \\
36,4\end{array}$ & $\begin{array}{c}28 \\
10,2\end{array}$ \\
\hline 15. Öğretim elemanları fakülte ile özdeştir. & $\begin{array}{c}8 \\
2,9\end{array}$ & $\begin{array}{c}95 \\
34,5\end{array}$ & $\begin{array}{c}108 \\
39,3\end{array}$ & $\begin{array}{c}54 \\
19,6\end{array}$ & $\begin{array}{l}10 \\
3,6\end{array}$ \\
\hline $\begin{array}{l}\text { 16. Fakülteye yeni gelen öğrencilerle eski öğrenciler çabuk } \\
\text { kaynaşırlar. }\end{array}$ & $\begin{array}{c}8 \\
2,9\end{array}$ & $\begin{array}{c}71 \\
25,8 \\
\end{array}$ & $\begin{array}{c}76 \\
27,6 \\
\end{array}$ & $\begin{array}{c}77 \\
28,0 \\
\end{array}$ & $\begin{array}{c}43 \\
15,6 \\
\end{array}$ \\
\hline $\begin{array}{l}\text { 17. Bu üniversitede Eğitim Bilimleri Fakültesi öğrencisi } \\
\text { olmak bir ayrıcalıktır. }\end{array}$ & $\begin{array}{c}67 \\
24,4 \\
\end{array}$ & $\begin{array}{c}79 \\
28,7 \\
\end{array}$ & $\begin{array}{c}45 \\
16,4 \\
\end{array}$ & $\begin{array}{c}42 \\
15,3 \\
\end{array}$ & $\begin{array}{c}42 \\
15,3 \\
\end{array}$ \\
\hline $\begin{array}{l}\text { 18. Fakültenin araştırma görevlileri öğrencilere içtenlikle } \\
\text { yardımcı olurlar. }\end{array}$ & $\begin{array}{l}25 \\
9,1\end{array}$ & $\begin{array}{r}128 \\
46,5\end{array}$ & $\begin{array}{c}55 \\
20,0 \\
\end{array}$ & $\begin{array}{c}40 \\
14,5\end{array}$ & $\begin{array}{l}27 \\
9,8\end{array}$ \\
\hline $\begin{array}{l}\text { 19. İdari personel öğrencilerin taleplerini karşılamada } \\
\text { olumlu bir tutum içindedirler. }\end{array}$ & $\begin{array}{c}6 \\
2,2\end{array}$ & $\begin{array}{c}79 \\
28,7 \\
\end{array}$ & $\begin{array}{c}85 \\
30,9 \\
\end{array}$ & $\begin{array}{c}66 \\
24,0 \\
\end{array}$ & $\begin{array}{c}39 \\
14,2\end{array}$ \\
\hline $\begin{array}{l}\text { 20. Fakültede öğrenci-hoca-personel arasında işbirliği ve } \\
\text { dayanışma vardır. }\end{array}$ & $\begin{array}{c}5 \\
1,8 \\
\end{array}$ & $\begin{array}{c}75 \\
27,3 \\
\end{array}$ & $\begin{array}{c}97 \\
35,3\end{array}$ & $\begin{array}{c}76 \\
27,6 \\
\end{array}$ & $\begin{array}{l}22 \\
8,0\end{array}$ \\
\hline $\begin{array}{l}\text { 21. Üniversite çağına gelen yakınlarıma bu fakülteyi tercih } \\
\text { etmelerini öneririm. }\end{array}$ & $\begin{array}{c}43 \\
15,6\end{array}$ & $\begin{array}{c}97 \\
35,3\end{array}$ & $\begin{array}{c}64 \\
23,3\end{array}$ & $\begin{array}{c}28 \\
10,2\end{array}$ & $\begin{array}{c}43 \\
15,6\end{array}$ \\
\hline $\begin{array}{l}\text { 22. Fakülte, aile, toplum ve iş dünyasındaki beklentileri } \\
\text { karşılamaktadır. }\end{array}$ & $\begin{array}{l}18 \\
6,5\end{array}$ & $\begin{array}{c}94 \\
34,2\end{array}$ & $\begin{array}{c}87 \\
31,6\end{array}$ & $\begin{array}{c}48 \\
17,5\end{array}$ & $\begin{array}{c}28 \\
10,2\end{array}$ \\
\hline 23. Öğrenciliğim sona erse bile, kendimi Eğitim Bilimleri & 50 & 93 & 57 & 41 & 34 \\
\hline
\end{tabular}




\begin{tabular}{|cl|c|c|c|c|c|}
\hline Fakülteli olarak göreceğim. & 18,2 & 33,8 & 20,7 & 14,9 & 12,4 \\
\hline 24. & Fakültenin fiziki mekânları diğer fakültelere göre farklı & 16 & 58 & 47 & 82 & 72 \\
& ve özgündür. & 5,8 & 21,1 & 17,1 & 29,8 & 26,2 \\
\hline 25. & Fakültede, açılıș, kuruluş, kapanış gibi günlerde & 20 & 81 & 60 & 74 & 40 \\
& törenlere önem verilir. & 7,3 & 29,5 & 21,8 & 26,9 & 14,5 \\
\hline 26. & Fakültenin geçmişine ilişkin anılar, öyküler, olaylar eski & 7 & 58 & 43 & 100 & 67 \\
& öğrenciler tarafindan yenilere aktarllı. & 2,5 & 21,1 & 15,6 & 36,4 & 24,4 \\
\hline 27. & Diğer üniversitelerin eğitim fakültelerinin aynı & 78 & 102 & 44 & 26 & 25 \\
& bölümündeki öğrenciler ile rekabette kendimi şanslı & 28,4 & 37,1 & 16,0 & 9,5 & 9,1 \\
görüyorum. & & & & & \\
\hline
\end{tabular}

